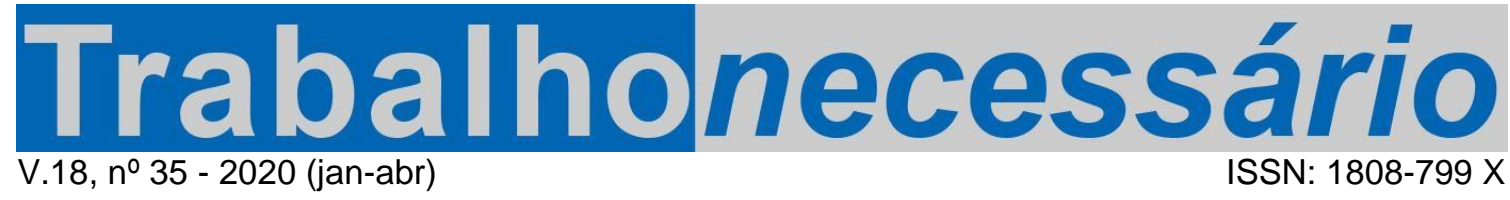

DOI: https://doi.org/10.22409/tn.v18i35.40488

\title{
Editorial
}

\section{ANO NOVO, VELHOS PROBLEMAS... E UM PRESENTE CHEIO DE POSSIBILIDADES}

\author{
Para onde vamos? \\ Ah, onde vamos parar? \\ Nessa encruzilhada, que estrada vamos pegar? \\ Que perigo de mau tempo, temporal. \\ De temperatura em alta e de desastre existe para todos nós, afinal? \\ Afinal? \\ Que desmatamento, incêndio ou inundação? \\ Nossos olhos tristes ainda inundarão? \\ Que geleiras tem que ainda derreter, \\ Pra quebrar a pedra de gelo que tem no peito, \\ quem tem um podre alto poder? \\ Quanto tempo vamos seguir sem de fato agir? \\ Contra a gana, por grana que aqui só faz destruir? \\ Quantos homens, aos milhares, aos milhões, \\ vão morrer de fome e de sede, \\ vitimas de ações de outros homens, de outras nações? \\ Que mundo nós \\ Deixaremos às gerações que virão após? \\ Que futuro preparamos, que manhã? \\ Que manhã? \\ Nosso tino ou desatino hoje define nosso destino, \\ Aqui. \\ Amanhã. \\ (Para onde vamos? \\ Música: Beto Villares, Letra: Carlos Rennó, 2019) \\ https://www.youtube.com/watch?v=QV6uYi189Mc
}

Como diz o dito popular, "Ano novo, vida nova". É quando desejamos um certo arrefecimento dos problemas e do stress do ano anterior, e um revigoramento de nossas forças para enfrentar o que virá. É por isso que em nosso primeiro Editorial do ano de 2020 escolhemos a letra da música de Beto Villares e Carlos Rennó como epígrafe: para que os questionamentos feitos por eles, com a sua arte, ecoem em nossas mentes e corações e nos ajudem a pensar nos desafios para a construção de 
um outro destino para a humanidade. Arte que expressa em perguntas fundamentais e se articula profundamente com a temática da TN 35, que tem na história - entendida como produção da existência - o seu eixo central.

Destacamos a dificuldade de realizar, neste espaço do Editorial, uma profunda análise de conjuntura ou mesmo uma avaliação das relações econômicas, políticas, sociais, culturais em que estamos imersos e que atingem todas as dimensões da vida humana, e da natureza. Entretanto, não queremos, com essa escrita, nos portar como Polianas (otimistas ao extremo), diante do quadro que se apresenta no plano nacional ou no internacional. Um quadro composto por retrocessos políticos, éticos e sociais, que parece nos levar de volta à Idade Média. A "caça às bruxas", com o antiintelectualismo, os cortes nas ciências, nas artes e na cultura, em geral, têm sido a resposta do neoconversadorismo e seus fundamentalismos (econômico, religioso, científico, político), por se sentir ameaçado pelas forças progressistas das sociedades.

Para combater os efeitos dessa força que nos assola, é preciso utilizar de todas as ferramentas possíveis, vindas dos mais variados campos, em especial do campo científico, para identificar, tocar corpos e mentes, compreender, interpretar com acuidade, para intervir com ações consistentes no meio social. Essa é, a nosso ver, a função da Ciência Comprometida.

O fundamental é pensarmos com amadurecimento necessário, com as lentes das teorias e experiências diversas e, acima de tudo, por perguntas que somos capazes de formular, que os espaços-tempos históricos trouxeram e trazem, para não só constatar ou analisar, mas transformar as relações sociais. Como dizia Marx, em A Ideologia Alemã: "Os filósofos se limitaram a interpretar o mundo de diferentes maneiras; o que importa é transformá-lo"1.

Assim, neste Ano Novo, invocamos que transformemos em ações os desejos que sempre nos tomam neste período, pois o desejo pode e deve ser convertido em ações, com o objetivo de acabar com os velhos problemas. Desejos, anseios e sonhos que se apresentam como um horizonte possível - nossa utopia. Por isso é que dizemos que o presente ou o ano que chega está prenhe e cheio de possibilidades, por entender que a história humana - com contradições e mediações diversas, como síntese de múltiplas determinações, como processo e como método, permite a

${ }^{1}$ Karl Max e Friedrich Engels em A Ideologia Alemã: introdução de Jacob Gorender; tradução de Luís Cláudio de Castro e Costa. São Paulo; Martins Fontes, 1989. 
apreensão da realidade em sua concretude, como elemento possível para análise de seus problemas.

E porque a história não tem fim, e nem tudo que dita o sistema capitalista, se efetiva de forma absoluta. Na verdade, são os sujeitos sociais os senhores da história; sujeitos encarnados e com lugares de pertencimentos específicos que podem transformar o caos que vivemos no momento. Os fatos estão postos, mas não definitivamente, porque é o movimento dos sujeitos sociais que faz com que tais fatos perdurem ou deixem de existir.

O sentido da vida está nessa disputa posta pelas lutas de classes, por distintos processos de construção societários, nos quais a educação, a saúde, a cultura, as ciências também são parte constitutivas. Por isso é que hoje, no presente, tanto como no passado, ideias contra-hegemônicas recebem ameaças constantes.

Em relação à arte, se ela não explica ou muda a realidade, ela, com as perguntas que nos traz, nos interroga, nos envolve, nos toca, nos emociona, nos faz sentir, sobretudo, as coisas do mundo e da vida. Nos faz pensar de que natureza humana nos constituímos. Nós, humanos, em relações diversas, com os outros homens, com a natureza. A arte canta, baila, declama, expressa teatralmente a realidade. Sozinha ela não muda a realidade, mas nos inspira a pensar e a sentir sobre ela. Ela é história. Ela também faz história.

No contexto que vivemos, sem desconhecer o papel dos movimentos sociais populares, é a arte que ainda grita, que não se cala. É ela que nos alerta sobre todo ser vivente. Vida em sociedade que às vezes queima, mas que ainda teima em se constituir. Nesse mundo, a arte faz agitar a nossa esperança, na medida que nos faz nos enxergar melhor, em um momento que o sistema capital tenta coisificar os humanos.

Por isso voltamos à pergunta feita por Villares e Rennó, colocada em nossa epígrafe: Para onde vamos?

E ao tentar respondê-la podemos pensar nas diferentes dimensões da vida humana, quando um contingente grande da população mundial e nacional, por pertencimento de classe, raça/etnia, gênero é excluído e impedido de usufruir dos bens materiais e imateriais que produz cotidianamente, o que acarreta mortes (físicas e simbólicas) das potencialidades humanas, apesar de todo o desenvolvimento tecnológico. 
O que a perversidade e pervesão do sistema capital e seus representantes tem realizado com a classe trabalhadora, com as contrarreformas? A perda dos direitos historicamente conquistados, alavancando as desigualdes sociais tais como o trabalho (desregulamentação e aumento do desemprego), a negação da previdência (saúde, aposentadoria, segurança), da educação, de acesso a cultura, a falta de moradia e de acesso/apropriação da terra, em detrimento da vida dos trabalhadores, das trabalhadoras e de seus filhos.

Uma nova diáspora forçada vem ocorrendo no mundo, por questões de ordem política e/ou econômica. Trabalhadores pobres, desprovidos de tudo, em situação de migração ou de imigração como refugiados, devido ao esfacelamento das democracias, ou por toda a riqueza produzida estar concentrada nas mãos de poucos, os mais ricos do planeta.

Especificamente no Brasil, a ofensiva do sistema capital pode ser percebida no desmatamento e nas queimadas da Amazônia (e seu impacto internacional), na poluição das águas, no desastre ambiental (Brumadinho sem resposta até hoje, as manchas de petróleo no mar), nos assassinatos no campo e na cidade (Quem matou Mariele, as lideranças indígenas e os moradores de rua?), na invasão e usurpação das terras indígenas, quilombolas e população ribeirinha, realizadas de diferentes formas; no retorno de algumas endemias, por causa da ausência do saneamento básico; no avanço e estímulo das propagandas nazi-facistas, e mais recentemente, nos golpes recebidos pela cultura e artes, com os cortes, proibições de espetáculos e atentados (Porta dos Fundos). No campo da educação, há a privatização de todas as etapas de ensino, inclusive a Educação Superior. A EAD - Educação à Distância caminha a passos largos. E na calada da noite surge uma nova versão do Future-se, que transforma-se em anteprojeto (24/12/19), ao mesmo tempo que surge a MP 914/2019, que ataca a democracia e a autonomia das Universidades, diante da escolha presidencial para reitor, retirando o que se tinha conquistado a partir dos anos 90 do Século $X X$, a lista tríplice.

Como sinaliza Carlos Augusto Aguilar, no Jornal da ADUFF (Dez de 2019/Jan de 2020$)^{2}$

\footnotetext{
${ }^{2}$ Associação Docente da UFF-SSind. Em 2020, a UFF se encontra (de novo) nas ruas. Niterói: Jornal da ADUFF-SSind, Dez de 2019/Jan de 2020.
} 
A medida tem essa tentativa de impor o Future-se através da nomeação do reitor pelos interesses políticos do [presidente] Bolsonaro. E foi dado o poder dos reitores nomearem os diretores das unidades. É uma maneira de concentrar um poder sem medida nas mãos dos reitores e dessa forma conseguir a aprovação do programa Future-se. Outro aspecto da medida resswaltado por ele [o diretor] envolve o ataque ideológico às instituições de ensino. Fica muito mais fácil realizar um controle das atividades acadêmicas".

Para além deste ataque, devemos estar atentos, por exemplo, diante da PEC Emergencial, que deve ser votada em fevereiro de 2020, e que pode reduzir salários e asfixiar serviços públicos. Caso aprovada, "proporcionará a curtíssimo prazo aquilo que a Emenda Constitucional 55 demoraria um pouco mais para fazer: a destruição dos serviços e dos servidores públicos (ADUFF-Ssind, id ibdem)".

Por fim, entendemos que esta forma perversa não ocorre somente com o campo da educação pública, mas se estende para todos os serviços públicos básicos destinados para a população, o que exige de todo o campo progressista atenção e ação coletiva. Neste sentido, utilizando a história e arte como companheiras de reflexão, conclamamos que uma unidade de esquerda seja construída, dentro da diversidade posta no contexto social, na medida que no ano de 2020 teremos eleições municipais, o pode reverberar no ano de 2022. Que nossas diferenças sejam pequenas em prol do que O Comum exige de nós. Esperamos que a TN 35 - História e historiografia em trabalho-educação seja profícua para a tarefa que cabe para todos nós. Sigamos avante!

José Luiz Cordeiro Antunes, Maria Cristina Paulo Rodrigues, Lia Tiriba Editores da Revista TN 